\title{
ARTICLE
}

\section{Elucidating the constructs happiness and wellbeing: A mixed-methods approach}

\author{
Janine Jongbloed · Lesley Andres
}

\begin{abstract}
In this study we examine the constructs "happiness" and "wellbeing" in a sample of Canadian women and men in mid-adulthood. Through a sequential mixed-methods approach, we utilize Sen and Nussbaum's conceptualizations of capabilities to inform the themes generated from semi-structured interviews. We find that participants understand happiness and wellbeing as two distinct constructs that are illuminated in the metaphors happiness as balance and the gears of wellbeing. Second, we corroborate these constructs through a principal component analysis of questionnaire data. We conclude that happiness and wellbeing are not static entities, but rather iterative processes that are constantly in flux and determined by the fulfillment of the often contradictory needs for (1) goal-achievement and an acceptance of reality, and (2) freedom along with meaning-making, which often involves creating restraints in one's life. These findings have important implications for those using happiness and wellbeing as policy outcome measures.
\end{abstract}

Keywords: happiness, wellbeing, interviews, survey research, mixed methods, Canada.

\section{Background}

The study of happiness, as well as the closely related terms life satisfaction, wellbeing, and subjective wellbeing (SWB), has grown in popularity over the past decades (Gilbert, 2006; Helliwell, Layard, \& Sachs, 2012; McMahon, 2006). Numerous literature reviews on this topic have been written in recent years within the discipline of psychology (e.g., Diener, Suh, Lucas, \& Smith, 1999; Dolan, Peasgood, \& White, 2008; Kahneman \& Krueger, 2006) and economics (e.g., Blanchflower \& Oswald, 2004; Helliwell \& Putnam, 2004). Human wellbeing has been described as "the ultimate 'dependent variable'," that is, the outcome from which all other outcomes derive importance (Helliwell \& Putnam, 2004, p. 1435). Other outcomes, such as income and occupational status attainments, are typically valued because they are perceived as contributing to wellbeing. The most exciting aspect of wellbeing research is that it unites different kinds of social scientists from around the world (Blanchflower \& Oswald, 2004). However, this leads to multiple and often contradictory theories and conceptions of wellbeing.

There are many different interpretations of wellbeing in the literature. These approaches can be separated into three main groups: Approaches that emphasize desire-fulfillment, which dominate the economic literature; approaches that focus on hedonic pleasure or "feeling good," which are prominent in the psychological literature; and approaches that propose lists or models of what people need, such as Nussbaum's (2011) objective list of capabilities and the eudaimonic approaches to wellbeing found in psychology (Jayawickreme, Forgeard, \& Seligman, 2012; Nussbaum, 2011). These can be summed up succinctly as "wanting," "liking," and "needing" theories (Dolan \& White, 2007), and have been classified into similar categories by other 
researchers (Parfit, 1984). Most approaches fall into one of these groups, although others attempt to unite the three into a holistic approach, such as the theory of "flourishing" proposed in different forms by Diener et al. (2010), Keyes (2002), and Seligman (2011). These models and their accompanying survey instruments have received considerable empirical support; however, largely missing in the literature are the voices of laypeople and their real-world understandings of these constructs (Hone, Jarden, Schofield, \& Duncan, 2014). An exploratory refinement of the concepts, presented here, allows us to bring the voices of people to the forefront, while considering all three theoretical strains and focusing on those that emerge most strongly in the data.

This study investigates several issues that remain unresolved. First, researchers are still unable to agree upon concrete definitions of happiness and wellbeing (Gilbert, 2006; Kahneman, 2011). Often, these terms are used synonymously. Second, despite growing interest in lay conceptions of happiness and wellbeing (McMahan \& Estes, 2010), such perspectives and opinions, especially by those who are not undergraduate psychology students, are largely missing in the literature (Delle Fave, Brdar, Freire, Vella-Brodrick, \& Wissing, 2011). The lack of real-world understandings is a vital gap in the academic literature on happiness, wellbeing, and flourishing (Hone et al., 2014).

A third unresolved issue centres on the fact that finding happiness may not be tantamount to finding meaning in life, both of which are often incorporated as important aspects of wellbeing (Grouden \& Jose, 2015; Jayawickreme et al., 2012; Marar, 2003). For example, meaning-making activities, such as work and family, may not always improve one's happiness, although they may add meaning, and happiness activities may not always add meaning to one's life. The tension between happiness and meaning requires further analysis, as a focus on one without the other results in an incomplete conceptualization of wellbeing (Nussbaum, 2008). Finally, as Blanchflower and Oswald (2004) point out, there are "limitations to wellbeing statistics" and it is "unlikely that human happiness can be understood without, in part, listening to what human beings say" (p. 1360). In this paper, we strive to refine the conceptualizations "happiness" and "wellbeing" using interview and questionnaire data to better understand how wellbeing can be operationalized to reflect the real world perspectives of individuals.

\section{Theoretical framework}

The guiding framework of this study is Amartya Sen's capability approach. Sen $(1985,1987,1999)$ and Martha Nussbaum (Nussbaum \& Sen, 1993; Nussbaum, 2003, 2011) make a distinction between capabilities and functionings when looking at quality-of-life issues. Capabilities are all the actions and states that a person is able to do and to be, while functionings are the actions and states actively realized (Nussbaum, 2011). The distinction between the two concepts allows for a unique examination of wellbeing. Sen's (1999) famous example is that of a fasting versus a starving person: these two people do not differ in functioning, but obviously differ very much in capability. One person is faced with an environment constraint, which is detrimental to his health, while the other has made a spiritual decision to forgo the food available to her. Thus, capabilities are not simply a person's abilities, but her freedoms or opportunities to achieve various functionings. This freedom resides in the person but the "political, social, and economic environment" (Nussbaum, 2011, p. 20) shapes these freedoms, in a bounded type of agency.

Sen's and Nussbaum's approaches are based in Aristotelian philosophy in that capabilities reflect "the various things a person may value doing or being" (Sen, 1999, p. 75). The valued functionings for an individual person "may vary from elementary ones, such as being adequately nourished and being free from avoidable disease, to very complex activities or personal states, 
such as being able to take part in the life of the community and having self-respect" (Sen, 1999, p. 75) . Nussbaum (2011) outlines a list of objective capabilities necessary for all people, while Sen prefers to rely on societies and groups to decide democratically which capabilities are important for them. Both define wellbeing as the real freedoms individuals possess to attain a life that they have reason to value.

Sen's account runs counter to a sole focus on subjective measures of happiness such as those found in utilitarian accounts; for example, measuring wellbeing as the number or type of goods that a person possesses, which neglects the person's own opinion of the value of the items concerned (Sen, 1987). These accounts often ignore the distribution of wellbeing in a society and other valuable outcomes other than positive emotion and are easily influenced by adaptation and mental conditioning. He asserts that "as a mental state concept, the perspective of happiness may give a very limited view of other mental activities" (Sen, 1985, p. 188) and argues that happiness and wellbeing are two separate constructs. He states that although "happiness is of obvious and direct relevance to wellbeing, it is inadequate as a representation of wellbeing" (p. 189). Wellbeing, as Sen (1999) defines it, is a much larger concept that includes multiple facets of a person's functionings and capabilities, only one of which is happiness. One's capability set determines one's wellbeing by providing one with the ability to live out a meaningful life that one has reason to value. Thus, Sen aligns wellbeing more closely with meaning-making opportunities and activities than with positive emotion.

\section{Method}

The purpose of this paper is to investigate whether participants understand and experience happiness and wellbeing as unitary or differentiated constructs, as described in Sen's (1985) argument above. Our analyses were rooted in a mixed methods approach, employing a sequential exploratory design (Creswell \& Plano Clark, 2011; Creswell, Plano Clark, \& Garrett, 2008).The two components (1) allow for an in-depth understanding of the differentiated constructs of happiness and wellbeing and (2) increase the construct validity of these two constructs through triangulation (Andres, 2012; Greene, 2007).

\subsection{Procedure}

We began by analyzing qualitative interview data (described below) with the intent to define and conceptualize "happiness" and "wellbeing" based on participants' own descriptions of these concepts. Using thematic coding in ATLAS.ti, we developed two metaphors to better illustrate and conceptualize participants' definitions of "happiness" and "wellbeing." The coding took place in three stages: The first author first transcribed all the relevant parts of the interviews, reread all the interviews multiple times, and then created thematic coding based on the participants' own wording and explanations. The second author, who also conducted the interviews, examined all the codes in conjunction with the interviews and suggested modifications. The modified codes were reduced to a more manageable number by the first author and then entered into ATLAS.ti and coded onto the transcripts in order to quantify the responses pertaining to each thematic coding.

In the second part of our analyses, we tested the constructs generated in the qualitative analysis by conducting a principal component analysis in STATA, employing the questionnaire data from the same population of individuals to corroborate these constructs. In both stages we interpret the data within the framework of Sen and Nussbaum's capabilities approach, using their conceptualizations of functionings and capabilities in relation to people's wellbeing. We conclude by exploring the implications of our findings for future research. 


\subsection{Participants}

The data employed in this paper are from the most recent wave of the Paths on Life's Way (Paths) longitudinal project and comprise two components: a mail-out questionnaire and face-to-face semi-structured interviews. The questionnaire component includes 574 respondents who are part of a stratified random sample of high school graduates of 1988 in British Columbia first surveyed in 1989 and then again in 1993, 1998, 2003, and 2010 (Andres, 2015). The interview component includes 24 participants who were interviewed six times between 1989 and 2012 by the principal investigator (PI) of this project. Our current analysis employs only the data collected in the 22-year follow-up. Questionnaires were mailed to respondents in $2010(n=574)$ and interviews were conducted in 2011-12 ( $n=24)$.

\subsection{Apparatus/Materials}

First, we employ interview data to determine how participants define and assess their own happiness and wellbeing. Qualitative data from the face-to-face interviews included responses to questions about participants' lives, work, education, and life choices, as well as questions about "happiness" and "wellbeing." In interviews conducted over a one-and-a-half- to two-hour period participants were also asked to answer questions regarding their happiness, stress, and health and were invited to discuss their responses (see Appendix A). Respondents to the mailout questionnaire answered five Likert-type questions related to happiness, stress, and health (the same questions that the interview participants answered), as well as more than 50 other questions related to their wellbeing. Overall, respondents to the mail-out questionnaire in this project reported themselves as happy and healthy, although the responses related to health showed greater variation (see Appendix B).

\section{Analyses and Findings}

\subsection{Definitions of Happiness and Wellbeing: Voices of the interview participants}

Several themes emerged from the qualitative data. When asked to rate themselves on the Likertscale happiness question, interview participants talked about many different domains of life, including family, work, leisure, and travel, and some themes cut across these domains and participants (see Table 1 below). The first theme that emerged was the idea that happiness is relative to what one can imagine. These were often upward comparisons: a comparison to what the participant could imagine her or his life looking like under ideal circumstances. Half the participants mentioned that they "could imagine better" when asked to rate their current happiness. As one participant stated, "I'm not a 10 because I can imagine myself eating ice cream on a beach somewhere."

A smaller portion of participants, four of the 24, made downward comparisons. One woman stated, "I really can't justify being unhappy," because of all the things she has in her life. This same participant further explained, "I don't have regrets, I don't have concerns, I don't have to worry about meeting basic needs, and I think that all goes hand-in-hand with being happy." In total, two-thirds of the participants measured their happiness by comparing their lives to an imagined, possible life and judging it relative to what it could be (see Table 1). This was both negative, if they could imagine things being better and were therefore less happy, and positive, if they could not imagine anything that would increase their present happiness. The examples above illustrate that sometimes not striving towards something more and simply accepting what one has may be instrumental to achieving happiness. 
Table 1a. Participants' responses to interview questions coded inductively by theme

\begin{tabular}{|c|c|c|c|}
\hline Theme & Code & Percentage & Example \\
\hline \multirow[t]{2}{*}{$\begin{array}{l}\text { Happiness } \\
\text { and } \\
\text { wellbeing... }\end{array}$} & Are separate & $85 \%$ & $\begin{array}{l}\text { They're probably different... When I think about wellbeing, I think about physical wellbeing, I think } \\
\text { about mental wellbeing. It seems like there are some people that are really physically not in a good } \\
\text { place, but are happy. }\end{array}$ \\
\hline & Are the same & $15 \%$ & I would put it the same. I don't think you can have wellbeing without being happy. \\
\hline $\begin{array}{l}\text { Rating } \\
\text { happiness: }\end{array}$ & To past & $30 \%$ & $\begin{array}{l}\text { Whereas my life growing up was filled with divorced parents, no money, divorced this, that, crazy } \\
\text { mom. I know that tomorrow things will be better, and things never get me down... }\end{array}$ \\
\hline \multirow[t]{3}{*}{ Comparisons } & To others & $20 \%$ & $\begin{array}{l}\text { I spend a lot of time being frustrated because I'm not where I should be and I see it as a failing of } \\
\text { myself. A lot of it is just my own perception. Not comparing what I have to what the neighbours have. } \\
\text { Not comparing what I have to other people in my grad class. }\end{array}$ \\
\hline & To imaginary: better & $50 \%$ & $\begin{array}{l}\text { Um, right now, probably about a four. Again, just because if I had a job that I actually didn't mind } \\
\text { doing... }\end{array}$ \\
\hline & To imaginary: worse & $20 \%$ & $\begin{array}{l}\text { I don't have regrets, I don't have concerns, I don't have to worry about meeting basic needs, and I } \\
\text { think that all goes hand-in-hand with being happy. }\end{array}$ \\
\hline \multirow[t]{6}{*}{$\begin{array}{l}\text { Happiness } \\
\text { as balance }\end{array}$} & Feel lack of freedom & $20 \%$ & $\begin{array}{l}\text { I feel like I spend too much of my day just doing mundane things that you have to do as part of your } \\
\text { life, but I don't feel like I have enough free time to do the things that I really like. }\end{array}$ \\
\hline & Desire more freedom & $20 \%$ & $\begin{array}{l}\text { And you know, I just want freedom, I guess is what I want. I want freedom to do the things I want to } \\
\text { do. }\end{array}$ \\
\hline & Have freedom & $25 \%$ & $\begin{array}{l}\text { I'm super grateful. I think I have a great life. I could literally drop dead tomorrow and feel like there's } \\
\text { no problem with that because I've done everything I've ever wanted to do up until today. }\end{array}$ \\
\hline & Achieving goals & $30 \%$ & I feel that all the goals I've set for myself, I've worked towards them, there's always new goals. \\
\hline & Acceptance/contentment & $25 \%$ & $\begin{array}{l}\text { Through different reading, and books, and through some professional guidance, I've discovered what } \\
\text { my skill sets are: I'm comfortable with who I am, I don't have to... I'm not dwelling on what I'm not } \\
\text { anymore. }\end{array}$ \\
\hline & $\begin{array}{l}\text { Balance: achieve and } \\
\text { accept }\end{array}$ & $20 \%$ & $\begin{array}{l}\text { I think the gauge for me is how fulfilled I am. So that's how I know that I need to get to the next level, } \\
\text { because I am fulfilled with what I do, but I definitely want to make it bigger and to have more. So } \\
\text { that's kind of how I measure my success and happiness. And for the most part it's there, but I think I } \\
\text { just aspire to have more, and to have even more meaning behind what I do. }\end{array}$ \\
\hline
\end{tabular}


Table 1b. Participants' responses to interview questions coded inductively by theme

\begin{tabular}{|c|c|c|c|}
\hline Theme & Code & Percentage & Example \\
\hline \multirow{6}{*}{$\begin{array}{l}\text { Gears of } \\
\text { wellbeing }\end{array}$} & Life-work balance & $30 \%$ & How I perceive or think about my mental health is always working towards that life-work balance. \\
\hline & Exercise & $40 \%$ & $\begin{array}{l}\text { Because I've been going to the gym, I feel quite a bit more healthy physically, because I can see the } \\
\text { increases I've made. Every time I go to the gym and I can lift an extra five pounds, or I go on the } \\
\text { treadmill for twenty minutes and jog, instead of just walk fast like I used to, I can see the improvement } \\
\text { there. }\end{array}$ \\
\hline & Family & $40 \%$ & $\begin{array}{l}\text { Having a nice work-life balance, being there for the kids. For us, I think that's something that we're } \\
\text { really trying to focus on as a family. }\end{array}$ \\
\hline & Feeling too busy & $30 \%$ & $\begin{array}{l}\text { Umm, trying to make it in [city name] and childcare and being frazzled all the time and working } \\
\text { really hard at work but not really feeling like I'm being successful necessarily, and then at home } \\
\text { always just not getting quality time with my kids, so I'm very grateful, but life feels quite tough. }\end{array}$ \\
\hline & Adjusting time/energy & $40 \%$ & $\begin{array}{l}\text { I like to keep my life simple. I have a very minimal amount of material things. I think I just realized } \\
\text { what makes me happy all this time, which is if I'm learning stuff and challenging myself, I'm the } \\
\text { happiest. So I basically directed my life in doing more of those things. And the things that entangle } \\
\text { me... I just don't bother with them. }\end{array}$ \\
\hline & Health problems & $25 \%$ & $\begin{array}{l}\text { Yeah, I turned } 40 \text { a couple weeks ago and leading up to that I just had so many aches and pains and I } \\
\text { just felt so unbelievably old and, you know, I had trouble getting out of bed }\end{array}$ \\
\hline
\end{tabular}


The idea that participants could "look back" and judge their happiness in comparison to other points in time arose in almost a third of the interviews. "I've come full circle... If you had asked me that two years ago or three years ago, I'd be like a 2." The idea that happiness is relative to other times in one's own life was also raised in relation to one's future. One participant expressed that the stress her oldest son caused her was "the only reason why I'm not a 10," but that she was looking to the future and "realize[d] that it will come." In contrast, three participants emphasized the importance of living in the present moment. One woman commented that "people focus too much on the past and then let the past identify who they are and let the past hold them back from doing things that wouldn't ordinarily do." Hence, although many people made comparisons across time, a smaller group also seemed to be resisting the tendency to do this.

The second theme consisted of the idea that happiness is an outlook or mental approach to life, and emerged in one third of the interviews. One man discussed at several points in his interview the fact that "I look at every situation and I don't look at it as being bad, I just look at it as a challenge... and looking forward through it." A female participant also mentioned the importance of one's perspective: She mused that we are often "unrealistic" in what we think we need to be happy. One man even argued that happiness was entirely outlook, entirely "a state of mind" and "what you make of your own world."

The importance of one's outlook on life was clearly illustrated in the fact that one participant who was suffering from a serious and rare health condition rated his happiness and mental health on par with the average of the other participants. This participant also rated his health ("between a four and five") as equal to that of several other participants who were concerned about their weight, illustrating the subjective and mental nature of these concepts. Although an outside observer looking into these two people's lives might guess that their happiness and health would be very different, they rated themselves at a similar point on these scales. The differing criteria for being healthy may be due to adaptive preferences (Nussbaum 2011; Sen 1999), which are preferences shaped by circumstance rather than true personal valuation and desire. Conversely, this may also simply shed light on what is important for happiness: As the participant mentioned above stated, a happy life may only require "having family and stuff like that; people, family, friends." This outlook shaped a happiness level quite contrary to what most might guess from the outside looking in, considering his objectively-measured physical health.

The last theme is the idea that happiness is freedom to do and be what one wants to do and be. The freedom theme cut across all the interviews and emphasizes the importance of Sen's (1985) concept of capabilities, as opposed to functionings. Participants' references to this concept were direct in half the interviews: for example, "I just want freedom... I want freedom to do the things I want to do." This focus on freedom was also expressed more indirectly. One way a participant did this was by describing happiness as "making decisions that are best to make you feel good inside." For all the interviewees, being able to "more or less live the way you want to live" was raised as an important precursor to happiness.

\subsubsection{Happiness is not wellbeing}

Almost all participants (more than three-quarters) differentiated between "happiness" and "wellbeing," although they all agreed that the two concepts were closely related to one another (see Table 1 above). The most common perspective was that "happiness is a part of wellbeing." As one woman stated, "I think wellbeing is more all-encompassing in terms of physical health as well as mental health, and happiness I consider to be more mental." She visualized it as "one feeds into the other" and that "happiness [is] one dimension of wellbeing." Similarly, another 
woman argued that happiness "is more a state of mood," while wellbeing is "more of how I am in the physical realm, the mental realm, the spiritual realm."

Contrasting this, three female participants felt that happiness was not a required part of wellbeing. As one stated, "I think you can have a general sense of wellbeing without being incredibly happy." Another stated that she thought that "your wellbeing can be good, ... but it doesn't necessarily mean that you're happy." In a similar vein, the third differentiated between wellbeing as doing the things you should do and happiness being doing the things you want to do. She stated that for wellbeing "you might pass up the cupcake," but for happiness "you eat it."

Conversely, three of the participants felt that happiness and wellbeing were so related that one could not occur without the other; for them, happiness was an integral part of wellbeing. One man asserted that he did not think one could "have wellbeing without being happy." Another argued, "In order to have a good wellbeing, you have to be a happy person." These participants believed that "it would be incomplete wellbeing if you weren't happy." Other participants thought that wellbeing was a necessary ingredient for happiness. "If you don't have a sense of wellbeing, then I don't think you can be happy," one woman asserted, and added, "You can be happy if you're not physically well, if you choose to overcome that mentally, but... wellbeing is the whole package, physically, emotionally."

Although a variety of views of happiness, wellbeing, and their relationship, were identified, there are a number of common threads that interconnect these views. All participants view happiness as a wholly mental concept, while wellbeing incorporates many other aspects, including a physical aspect. Surprisingly, almost all participants defined happiness as a balanced, calm, and everyday type of notion. None defined happiness in terms of ecstasy or being out of balance. Also, they recognized unanimously that happiness was not a constant state of mind, but rather something that would change over time. More than half mentioned freedom as important to their happiness in life, with a lack of freedom leading to lower scores for $40 \%$ and the presence of freedom leading to increased happiness for $25 \%$ (see Table 1). Their responses mesh well with Sen's (1985) assertion that although "happiness is of obvious and direct relevance to wellbeing, it is inadequate as a representation of wellbeing" (p. 189). Also, they clearly corroborated Sen's (1985) argument that "happiness is basically a mental state, and it ignores other aspects of a person's wellbeing" (p. 188). From these findings, two metaphors emerged to guide us toward understanding these concepts.

\subsubsection{Happiness as balance}

One noticeable tension in participants' ways of measuring their happiness is between two main ideas that surfaced in almost all of the interviews. The first is setting goals and achieving them as a way to happiness, and the other is being content and not always striving for more. A quarter of the participants mentioned each of these themes directly, and more mentioned these indirectly. Often the same participant would raise both of these aspects. On the one hand, participants approached happiness as something "rational," something to strive for and that could be accomplished; on the other hand, they emphasized the need to accept those things that were out of their control and find acceptance with many aspects of life which did not go according to plan (see Figure 1).

Thus, it seemed that happiness, as one part of an overall sense of wellbeing, emerged from the balance between being able to and actually achieving desired goals, as well as maintaining an attitude of acceptance or contentment to what actually occurs in one's life. As expressed by one man, this balance can arise from the ability to "live within your means and not always be 
striving for something else, but really be able to appreciate what [you've] got, but to have meaningful challenges to work towards". One third of participants pointed out that when they were "more balanced" they felt happier, and that being "out of balance" was a hindrance to happiness.

Figure 1. Happiness as balance

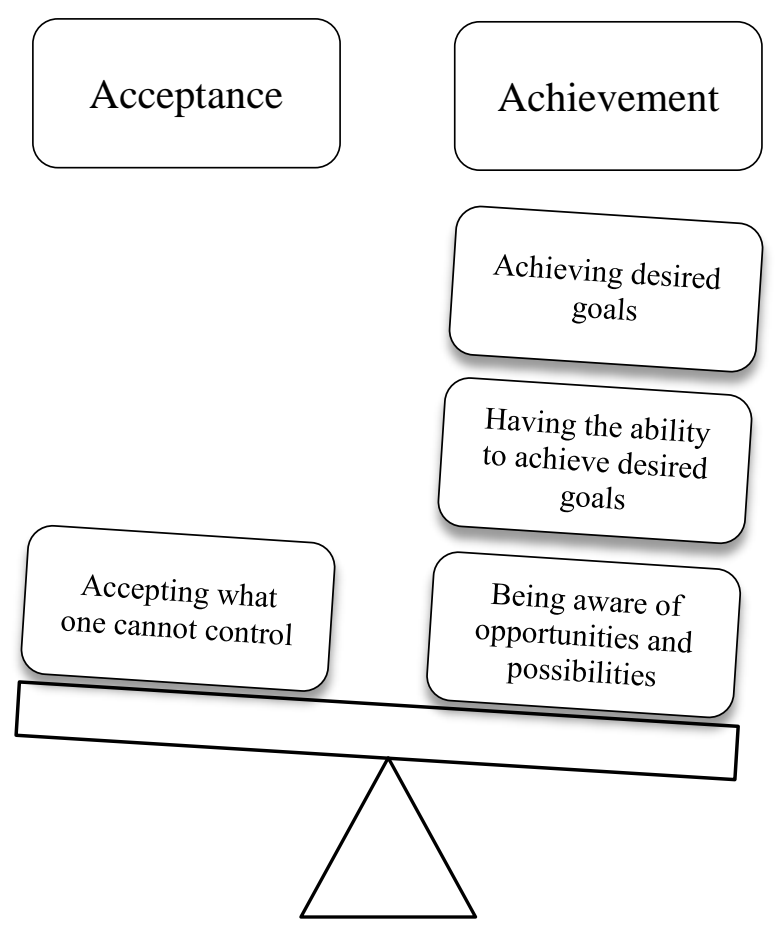

The idea that happiness is related to accomplishing goals or attaining desired outcomes in one's life was stated directly in a quarter of the interviews. However, these goals were not usually in relation to money or "things." One such valued goal was creating a family; in fact, the idea of the "happy family" came up in almost every interview, and $40 \%$ mentioned this as very important to their happiness. Happiness in life was often equated with "children" or other familial and interpersonal concepts, particularly by female interviewees. However, spending time with their spouses and children emerged as important for all participants who had spouses and children. As such, goals took different forms and were as much - or more - related to participants' personal lives than work lives. The value of having achievable goals in relation to happiness has been discussed by many other researchers (e.g., Diener et al., 1999) and these goals need not be material or career-related. Spending time with loved ones reflects the experiences described by many of the interview participants.

Other authors have theorized happiness in ways similar to Paths interview participants in terms of balance. For example, Marar (2003) contrasts freedom and justification (or meaningmaking) in his conceptualization of happiness. Meaning-making entails creating a sense of order and purpose in life through the pursuit of goals (Grouden \& Jose, 2015). This way of viewing happiness as a balancing act between being able to do what one wants, but also being tied to meaningful people and activities, fits well with the notions that participants mention in their interviews. There is a constant tension between what people "should" do, have, and be in order to be happy and the related loss of freedom this may cost them. This loss of freedom seems to be a cost in quality of life in itself, and also appears to take a toll on the happiness of the interviewees. Conversely, a lack of possessions, relationships, and career or work responsibilities can also be 
detrimental to wellbeing. Marar (2003) deals extensively with the tension between creating meaning in life and having freedom, claiming that it is at the root of the unattainable and elusive qualities of happiness. Participants also alluded to this in their descriptions of how happy they were and how they defined happiness. One can infer from their statements that there is never a permanent state of balance: throughout their ever-changing lives, participants are continuously shifting the balance, resulting in different levels of happiness.

\subsubsection{The "gears" of wellbeing}

From the themes generated at the beginning of this section, and the ways in which participants rated and elaborated on their own happiness, several key ideas become apparent. Happiness is not constant, but rather varies over time, and comparisons across time impact happiness levels; happiness is influenced by a variety of valued domains of life, and the importance of each domain changes over time, but the most important ingredient in life is optimal balance between these domains. And, finally, happiness is only a part of a person's overall wellbeing, which is more all-encompassing, and the importance of happiness itself may vary over time and situation.

From these ideas emerges a metaphor for wellbeing: wellbeing can be visualized as a set of interlocking gears (see Figure 2). This metaphor is similar but distinct from the "engine of wellbeing" metaphor used by Jayawickreme et al. (2012). Although these researchers focus on inputs, process, and outcome variables, working on the basis of earlier systems-theory approaches, our metaphor focuses on how this would unfold within individuals' lives. This modification focuses on the ability of individuals to adjust their approach to life based on exterior events and resources. The metaphor of bicycle gears, as opposed to an engine, lends a more useful frame of reference for this purpose.

\section{Figure 2. Gears of Wellbeing}

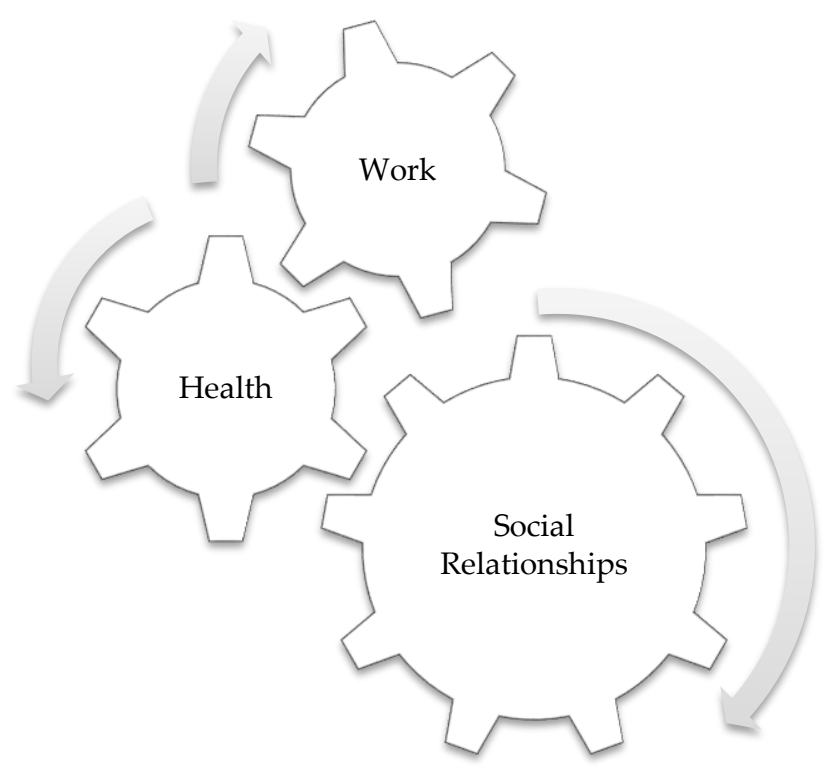

This simple machine, a transmission consisting of many gears working in tandem, which is visualized with three gears but more accurately would include many more, produces mechanical advantage if properly aligned and if all the gears are moving smoothly. Metaphorically, "mechanical advantage" represents optimal levels of wellbeing at a certain point in a person's life, which produces happiness, and these optimal levels change over time and situation. 
Metaphorical mechanical advantage could also be gained through different gear ratios, which would mean adjusting the "gears" of social relationships, health, work, and others in order to maintain optimal efficiency as well as functioning. This is equivalent to the process component of Jayawickreme et al.'s (2012) engine model, which includes personal choices based on the input variables. In the metaphor of the bicycle gear, these ratios would change over time to produce similar overall mechanical advantage.

For example, a difficult period of time in a person's life, such as dealing with the death of a loved one, could be thought of as riding up a hill - it is necessary to change gears to get to the top, but once there one can switch back to a different combination in order to again gain mechanical advantage. Optimal wellbeing requires different gear ratios when one is in university at the age of 22 than when at the age of 40 one has children and a mortgage. Surrounding this metaphor is the first metaphor of balance based on Sen's idea of capabilities and functionings. One changes gears, or focus and energy, between aspects of wellbeing, while also balancing the need for both achievement and acceptance for happiness. One needs the freedom and ability to switch between these gears, and if one gets "stuck," the entire machine will stall. Similarly, if one leans too much towards either acceptance or achievement, balance will be lost. Both of these situations would result in a person having less optimal wellness.

Although this idea seems quite logical and mechanistic for something as ethereal as wellbeing, all participants exhibited this type of mindset to greater or lesser degrees. For the most part, they believed that they could more or less plan their lives, and happiness was often mentioned as an explicit goal of this planning. As one woman emphasized, it is "rational to try to be happy" and to act to promote one's happiness. Many of the participants set goals in relation to happiness and felt that they could control their happiness to a certain degree. Importantly, those who mentioned experiencing a sense of control over their happiness often scored themselves as happier than those who did not. Some participants were wary of setting "unrealistic" expectations for happiness and some were willing to put happiness "on hold" while accomplishing other things. The inability to consistently make happiness a priority may be partly due to the "acceleration of time" (Rosa, 2003) as "life becomes layered with multiple tasks, responsibilities, and options" (Andres \& Wyn, 2010, p. 191). In line with Sen (1999) and Kahneman (2011), people might have goals that transcend their current wellbeing and happiness, but which might deliver future happiness.

The interlocking gears of wellbeing include many domains of life. The three central domains that arose in all interviews were, in order of importance: social relationships, physical and mental health, and work (as shown in Figure 2). Interview participants talked about struggling to keep their family lives and their work lives moving in harmony; however, most spent a much greater portion of the interview discussing family than work. Work was described almost entirely in terms of stress and this was described as detracting from happiness by almost half the participants. In regard to time, none mentioned wanting more time for work, but many wanted "more time with family" and "more time with friends." Andres and Wyn (2010) also found that even though the importance participants placed on "succeeding at work or a career and having enough money to live well" declined over the 15-year period they examined, almost no one rated these as unimportant, and approximately half rated these as very important; however, "relationships with partners, children, parents, and friends continued to be rated as very important" over time (p. 86).

When adjusting the "gears of wellbeing," individuals must make complicated decisions based on their capabilities, knowledge, prior experiences, and best guesses about the future. As Elster (2009) explains in his outline of rational action, individuals must choose "among the 
options of which [they are] aware according to the possible consequences [they] attribute to them," (p. 23) which are shaped by their desires, beliefs, and the information they receive - all mutually influencing one another. Rubenson and Desjardins (2009) also discuss the complexity of this type of decision-making. They emphasize Sen's (1999) assertion that capabilities and functionings depend not only on external and internal resources, but also on "individuals knowing about the range of possibilities of how these resources can be used to realize things that matter to them and knowing how to do so" (Rubenson \& Desjardins, 2009, p. 196). These decisions are further complicated by the fact that participants must forecast their emotional reactions to future events when making choices, and research suggests that people may not always do so accurately (Dunn, Brackett, Ashton-James, Schneiderman, \& Salovey, 2007; Kahneman \& Krueger, 2006; Kahneman, 2011).

Wellbeing, then, relies upon prior experience and a view to the future within multiple life domains, as well as the operation of these different aspects in synchrony with one another and within a person's life. In this complicated process, wellbeing may also depend "less on the objective events one encounters than on how those events are construed, dealt with, and shared with others" (Dunn et al., 2007, p. 7). In particular, due to the unpredictable nature of the future, participants were constantly making decisions within the context of uncertainty. The ongoing process of valuing, aligning, and balancing various parts of life is a process in which participants more or less "consciously manage their wellbeing" (Andres \& Wyn, 2010, p. 191), which may represent a new form of consumption that relies on both material and immaterial goods. People might participate in certain activities or purchase particular goods with the explicit goal of increasing their wellbeing. This is also an individualistic endeavour, as one woman's comments illustrate:

It's my personal belief that I'm responsible for me, nobody else is responsible for me, and if I'm unhappy, that's my own fault... So, I'm responsible for my own wellbeing, and I'm also responsible for my happiness, but I think of the two as totally separate, so I can have a sense of wellbeing but not be happy.

Now we turn to the questionnaire data to determine whether these concepts can be corroborated with a larger sample.

\section{Corroborating the constructs Happiness and Wellbeing}

Approximately 100 questions (including the sub-questions) about health, wellbeing, and happiness were included in the "Health and Wellbeing" section of the mail-out Paths on Life's Way questionnaire. In this section, 53 of the questions that were relevant and overlapped with the questions asked and topics raised in the interviews were used in the ensuing analysis (interview questions 2 to 6 in Appendix A were identical to the Likert-type items on the survey). We used principal factor analyses (PFA) with both Varimax and Oblimin rotation in STATA to determine whether similar themes from the interview data emerged in the survey respondents' responses to the happiness and wellbeing-related questions on the 2010 Paths on Life's Way survey.

The results of these analyses are reported in Tables 2 and 3 below. We excluded (1) factors with eigenvalues of less than 1.0 and items that did not load onto any of the factors with a factor loading of at least 0.30 and (2) survey items that were indicated as "not applicable" by more than 50 participants (e.g., spending time with children; caring for elderly relatives.) The best-fitting model statistically and theoretically was a four-factor model from the PFA with Varimax rotation that explained $62 \%$ of the variance $(N=525$, see Tables 3 and 4$)$. The PFA with Oblimin rotation, 
which has the advantage of assuming that the survey items are correlated, created the same groupings, with the exception of mental health, which loaded more strongly with overall satisfaction in this model, and satisfaction with work, which again loaded onto the first factor.

Table 2. Factor loadings of survey items using PFA with Varimax rotation

\begin{tabular}{lcccc}
\hline Items & Factor 1 & Factor 2 & Factor 3 & Factor 4 \\
\hline Overall happiness & 0.39 & - & - & - \\
Exciting life & 0.32 & - & - & - \\
Satisfied with personal life & 0.46 & - & - & - \\
Satisfied with family life & 0.45 & - & - & - \\
Satisfied with life these days & 0.31 & - & - & - \\
Satisfied with life to date & 0.41 & - & - & - \\
Physical health & - & 0.57 & - & - \\
Mental health & - & 0.30 & - & - \\
Satisfied with health & - & 0.50 & - & - \\
Satisfied with fitness level & - & 0.48 & - & - \\
Satisfied with time for activities & - & - & 0.42 & - \\
Satisfied with leisure time & - & - & 0.50 & - \\
Satisfied with personal time & - & - & 0.55 & 0.49 \\
Satisfied with time for friends & - & - & 0.40 & 0.57 \\
Satisfied with work/career & - & - & - & 0.51 \\
Satisfied with education & - & - & - & 0.34 \\
Satisfied with money & - & - & - & - \\
Satisfied with time for work & - & - & - & - \\
\hline
\end{tabular}

The first factor, which we have labeled evaluative happiness, comprises the largest group of survey items and includes respondents' ratings of the following: general life happiness, how exciting their lives were, satisfaction with their lives these days, and satisfaction with the way their lives had unfolded to date. This maps onto participants' general assessments and evaluations of their lives as a whole, which we could also term "judgmental happiness," an evaluative stance on one's happiness in life overall (Gilbert, 2006; Kahneman, 2011).

The second factor, health, was also an important theme emerging from the interviews. Physical health, mental health, satisfaction with fitness level, and satisfaction with health generally loaded strongly onto this factor. These clearly map onto a theoretical construct, and neatly fit into the "health gear" introduced in the gears of wellbeing metaphor.

The third factor, time for activities, friends, and self, includes respondents' satisfaction with the amount of time they have to spend on activities they enjoy, satisfaction with time for leisure and friends, and personal time. Time was highly valued and sought after, as mentioned in almost all of the interviews; a third of the participants mentioned that they felt too busy in their lives and would like to slow down. This is slightly different from the "social relationships gear" mentioned above; however, because it incorporates the notion of personal relationships as well, this could be an extension of that concept.

The final factor - satisfaction with career, education, and finances - comprises survey items related to work, career, and education. This includes satisfaction expressed by respondents with their educational attainments, satisfaction with work and career, and satisfaction with the time they spent at work. Satisfaction with the amount of money they earned also loaded onto this 
factor, suggesting that one discrete and important part of wellbeing related to both work and the material conditions of their lives. However, time for work and satisfaction with money was no longer significant when using an Oblimin rotation. This can be seen as corroborating the interview data, where interview participants attached much less importance to work in regard to their wellbeing and judgments of their happiness with life than they attached to family, health, and personal goals. This final factor is also the final gear in the gears of wellbeing metaphor.

Table 3. Factor loadings of survey items using PFA with Oblimin rotation

\begin{tabular}{lcccc}
\hline Items & Factor 1 & Factor 2 & Factor 3 & Factor 4 \\
\hline Overall happiness & 0.82 & - & - & - \\
Exciting life & 0.61 & - & - & - \\
Satisfied with personal life & 0.84 & - & - & - \\
Satisfied with family life & 0.73 & - & - & - \\
Satisfied with life these days & 0.78 & - & - & - \\
Satisfied with life to date & 0.85 & - & - & - \\
Physical health & 0.39 & 0.72 & - & - \\
Mental health & 0.57 & 0.42 & - & - \\
Satisfied with health & 0.46 & 0.62 & - & - \\
Satisfied with fitness level & - & 0.54 & - & - \\
Satisfied with time for activities & 0.40 & - & 0.62 & - \\
Satisfied with leisure time & - & - & 0.56 & 0.43 \\
Satisfied with personal time & - & - & 0.72 & 0.38 \\
Satisfied with time for friends & - & - & 0.51 & - \\
Satisfied with work/career & 0.55 & - & - & - \\
Satisfied with education & 0.37 & - & - & - \\
Satisfied with money & - & - & - & - \\
Satisfied with time for work & - & - & - & - \\
\hline
\end{tabular}

The results of the PFA analyses mirror those of the interviews in that happiness and wellbeing emerge as separate factors, and wellbeing itself is broken into separate factors that mirror the metaphor of gears working in synchrony. Thus, the metaphors from the qualitative analysis are again useful when looking at these four factors and how they might relate to each other. The quantitative analyses reemphasize the importance of close personal relationships, and the extent to which evaluative happiness varies with these variables. Interestingly, satisfaction with one's personal life and family life also load strongly onto the first factor in all models. Thus, as also identified in the interviews, family is inseparably intertwined with judgments about one's happiness and satisfaction with life in general. Other variables impact both happiness and wellbeing, but none follow so closely the variations in happiness as one's close social connections. This reflects the interview participants' notions of happiness: Happiness is an inherently subjective and mental view of oneself and one's life, closely related to wellbeing, but conceptually distinct from it.

\section{Limitations}

First, generalizing results from the survey sample is limited in that the sample is by definition restricted to high school graduates in British Columbia, Canada, 22 years after graduation, at 40 years old; hence, these results may not be transferable beyond groups similar in age and regional 
context. Second, these data are not analyzed by cultural groups, as to do so would be impractical with our sample size in a strongly multicultural place like British Columbia. Third, there is a slight bias in the survey sample towards those who have completed some form of higher education. However, as asserted by Andres and Adamuti-Trache (2008), although "the sample has been affected by attrition with a slight bias toward women and those continuing postsecondary education... overall it has remained remarkably representative of the original participant group" (p. 118). They maintain, "the degree of sample bias suggests that the findings... are generalizable to similar populations" (Andres \& Adamuti-Trache, 2008, p. 141).

\section{Discussion and Conclusions}

The purpose of this paper was to investigate in a mixed-methods approach whether participants understand and experience happiness and wellbeing as unitary or differentiated constructs. Using qualitative interview data we found that participants view these two concepts as separate; and we were able to create two metaphors to illustrate the participants' understandings of happiness and wellbeing. We corroborated these results using quantitative survey data and our PFA analyses illustrate that there are distinct portions of wellbeing that include family, health, personal time, work, and education. Through PFA we were not able to investigate the notion of balance, which was central to the happiness metaphor; however, survey respondents, like the interview participants, indicated in open-ended questionnaire comments that they engaged in an ongoing act of balancing acceptance and achievement in order to achieve an overall sense of happiness (Andres \& Wyn, 2010). The qualitative data suggest that this balance spans many areas of life and operates alongside another more objective and palpable function: ensuring that various domains of life turn in synchrony, much like a simple machine with interlocking gears.

These findings align with the distinction that Raibley (2011) makes between happiness and wellbeing as discrete concepts. His argument is consistent with that of Sen (1993) in that it proposes that happiness contributes to wellbeing only when it is valued and is therefore a necessary, but not sufficient, condition for high levels of wellbeing. He criticizes the approach taken by many researchers who approach happiness from a utilitarian standpoint and who use the terms happiness, wellbeing, satisfaction, and others, as interchangeable (for example, Van Praag \& Ferrer-i-Carbonell, 2008). Raibley (2011) defines episodic happiness as "the property of feeling happy at a time" (p. 1108) and suggests that although we often use the word happiness in daily speech in this sense, what we usually want to measure in social science research is a deeper and more stable sense of happiness that is more akin to wellbeing. The responses of most of the interviewees reflect this definition. To them, wellbeing was always seen as a conglomerate of many aspects of life and one's physical and mental being, while happiness was more mental and more fleeting.

We created two metaphors to summarize and define participants' understandings of happiness and wellbeing. This study suggests that people engage in an ongoing act of balancing acceptance and achievement in order to be happy. This balancing act requires that people be capable of achieving various valued states and goals, and also that they actually achieve some of these, aligning the participants' perspectives with that of the capability approach. This balance spans many areas of life, and exists as part of an overall sense of wellbeing that consists of various domains of life turning in synchrony, much like the metaphor of interlocking gears. Also, our findings indicate that tensions may arise between different aspects of wellbeing, and that these may need to be shifted in order to allow for all aspects of life to exist in a harmonious relationship that does not stifle any at the expense of the others. 
This balancing act is unique to each individual and changes with time; however, every participant mentioned the importance of social relationships in their interviews. Delle Fave et al. (2011) also found that happiness was "primarily defined as a condition of psychological balance and harmony" and that "family and social relations" were most prominent among the life domains associated with happiness (p. 185). Kahneman (2011) agrees with this assertion, positing that "[i]t is only a slight exaggeration to say that happiness is the experience of spending time with people you love and who love you" (p. 395). This underscores the importance of Nussbaum's (2011) inclusion of "affiliation" on her list of central capabilities.

These findings also lend support to the "flourishing" models of wellbeing. A recent article compared the four extant scales of Keyes (2002), Diener and others (2010), Seligman (2011), and Huppert and So (2013) for measuring flourishing both conceptually and empirically. They found that all four tap into both feeling and functioning, and include positive relationships, engagement or interest, and meaning and purpose (Hone et al., 2014). Each model differs in the other components; however, this study lends "real world" support to the notion that wellbeing does include each of these attributes and cannot be simplified to a hedonistic conception of happiness. Distinct groupings of wellbeing variables were found in both the interview and mailout survey data. More work is needed to clarify in detail which model of flourishing comes closest to reflecting laypeople's understandings.

Finally, participants were guided towards an evaluative notion of happiness in the wording of interview and survey questions, which might overlook the temporal nature of happiness (KimPrieto, Diener, Tamir, Scollon, \& Diener, 2005). Happiness researchers have been divided into different "camps," some of whom examine happiness in the moment, "emotional happiness" or "experienced wellbeing," and others who look at more general evaluations including larger time frames, "judgmental happiness" or "life satisfaction" (Gilbert, 2006; Kahneman, 2011). The questions used for the current study were framed from an evaluative rather than emotional standpoint; however, we believe that it is difficult to completely disentangle the two. Others argue that we act more for the benefit of our "remembering" than our "experiencing" selves (Kahneman, 2011). This argument is supported by the remark of one female interviewee: "I think that's the biggest thing: Creating really powerful, profound, lasting memories." As such, in the present study and for the purposes of this analysis, the focus is on happiness as a judgment of one's life, with the recognition that short-term, moment-to-moment emotion will also play an important role in these judgments.

Internationally, happiness is used increasingly to measure progress, as in the example of the government of Bhutan, which uses Gross National Happiness (GNH) as its measurement of national progress. Researchers such as Helliwell and Barrington-Leigh (2010) recommend that direct measures of subjective well-being (SWB) be used in making public policy decisions. In this study, we suggest that rather than simply measuring happiness or life satisfaction, it is more meaningful to attempt to uncover a more holistic measure of wellbeing, which the participants differentiated from happiness. This confirms the conclusions of other researchers (e.g., Hone et al., 2014; Jayawickreme et al., 2012). The findings of the current study can help inform future research on how to measure these constructs in operationalizations that are meaningful for people's daily lives, and to help promote balance and a focus on all parts of life - social, familial, physical, as well as work-related and educational - as a way to promote happiness and wellbeing.

\section{Acknowledgments}

This research was supported by the Social Sciences and Humanities Research Council of Canada. 


\author{
Authors \\ Janine Jongbloed \\ IREDU/Université de Bourgogne \\ Janine_Jongbloed@etu.u-bourgogne.fr \\ Lesley Andres \\ The University of British Columbia
}

\title{
Publishing Timeline
}

Received 30 September 2014

Accepted 11 May 2015

Published 30 July 2015

\section{References}

Andres, L. (2012). Designing and doing survey research. Toronto, Ontario: Sage.

Andres, L. (2015). A look back: A retrospective analysis of the sequence of life course events over 22 years. Vancouver, British Columbia. http://www.bccat.ca/pubs/ALookBack report Jan2015.pdf

Andres, L., \& Adamuti-Trache, M. (2008). Life-course transitions, social class, and gender: a 15-year perspective of the lived lives of Canadian young adults. Journal of Youth Studies, 11(2), 115-145. http://dx.doi.org/10.1080/13676260701800753

Andres, L., \& Wyn, J. (2010). The making of a generation: The children of the 1970s in adulthood. Toronto, Ontario: University of Toronto Press.

Blanchflower, D. G., \& Oswald, A. J. (2004). Well-being over time in Britain and the USA. Journal of Public Economics, 88(7-8), 1359-1386. http://dx.doi.org/10.1016/S0047-2727(02)00168-8

Creswell, J. W., \& Plano Clark, V. L. (2011). Designing and conducting mixed methods research. Thousand Oaks, CA: Sage.

Creswell, J. W., Plano Clark, V. L., \& Garrett, A. L. (2008). Methodological issues in conducting mixed methods research designs. In M. M. Bergman (Ed.), Advances in mixed methods research (pp. 66-83). London, UK: Sage Publications, Inc.

Delle Fave, A., Brdar, I., Freire, T., Vella-Brodrick, D., \& Wissing, M. P. (2011). The eudaimonic and hedonic components of happiness: Qualitative and quantitative findings. Social Indicators Research, 100(2), 185-207. http://dx.doi.org/10.1007/s11205-010-9632-5

Diener, E., Suh, E. M., Lucas, R. E., \& Smith, H. L. (1999). Subjective well-being: Three decades of progress. Psychological Bulletin, 125(2), 276-302. http://dx.doi.org/10.1037/0033-2909.125.2.276

Diener, E., Wirtz, D., Tov, W., Chu, K.-P., Choi, D., Oishi, S., \& Biswas-Diener, R. (2010). New well-being measures: Short scales to assess flourishing and positive and negative feelings. Social Indicators Research, 97, 143-156. http://dx.doi.org/10.1007/s11205-009-9493-y

Dolan, P., Peasgood, T., \& White, M. (2008). Do we really know what makes us happy? A review of the economic literature on the factors associated with subjective well-being. Journal of Economic Psychology, 29(1), 94-122. http://dx.doi.org/10.1016/j.joep.2007.09.001

Dolan, P., \& White, M. P. (2007). How can measures of subjective well-being be used to inform public policy? Perspectives on Psychological Science, 2(1), 71-85. http://dx.doi.org/10.1111/j.1745$\underline{6916.2007 .00030 . x}$

Dunn, E. W., Brackett, M., Ashton-James, C., Schneiderman, E., \& Salovey, P. (2007). On emotionally intelligent time travel: individual differences in affective forecasting ability. Personality $\mathcal{E}$ Social Psychology Bulletin, 33(1), 85-93. http://dx.doi.org/10.1177/0146167206294201

Elster, J. (2009). Reason and rationality. Princeton, NJ: Princeton University Press.

Gilbert, D. (2006). Stumbling on happiness. Toronto, Ontario: Vintage Canada.

Greene, J. C. (2007). Mixed methods in social inquiry. Hoboken, NJ: John Wiley \& Sons. 
Grouden, M. E., \& Jose, P. E. (2015). Do sources of meaning differentially predict search for meaning, presence of meaning, and wellbeing? International Journal of Wellbeing, 5(1), 33-52.

Helliwell, J. F., \& Barrington-Leigh, C. P. (2010). Viewpoint : Measuring and understanding subjective well-being. Canadian Journal of Economics, 43(3), 729-753. http://dx.doi.org/10.1111/j.15405982.2010.01592.x

Helliwell, J. F., Layard, R., \& Sachs, J. (2012). World happiness report. New York, New York. http://www.earth.columbia.edu/sitefiles/file/Sachs Writing/2012/World Happiness Report.pdf

Helliwell, J. F., \& Putnam, R. D. (2004). The social context of well-being. Philosophical Transactions of the Royal Society of London. Series B, Biological Sciences, 359(1449), 1435-46. http://dx.doi.org/10.1098/rstb.2004.1522

Hone, L. C., Jarden, A., Schofield, G. M., \& Duncan, S. (2014). Measuring flourishing : The impact of operational definitions on the prevalence of high levels of wellbeing. International Journal of Wellbeing, 4(1), 62-90. http://dx.doi.org/10.5502/ijw.v4i1.4

Huppert, F., \& So, T. (2013). Flourishing across Europe: Application of a new conceptual framework for defining well-being. Social Indicators Research, 110(3), 837-861.http://dx.doi.org/10.1007/s11205-0119966-7

Jayawickreme, E., Forgeard, M. J. C., \& Seligman, M. E. P. (2012). The engine of well-being. Review of General Psychology, 16(4), 327-342. http://dx.doi.org/10.1037/a0027990

Kahneman, D. (2011). Thinking, fast and slow. Toronto, Ontario: Doubleday Canada.

Kahneman, D., \& Krueger, A. B. (2006). Developments in the measurement of subjective well-being. The Journal of Economic Perspectives, 20(1), 3-24. http://dx.doi.org/10.1257/089533006776526030

Keyes, C. L. M. (2002). The mental health continuum: from languishing to flourishing in life. Journal of Health and Social Behavior, 43(2), 207-22. http://dx.doi.org/10.2307/3090197

Kim-Prieto, C., Diener, E., Tamir, M., Scollon, C., \& Diener, M. (2005). Integrating the diverse definitions of happiness: A time-sequential framework of subjective well-being. Journal of Happiness Studies, 6(1), 261-300. http://dx.doi.org/10.1007/s10902-005-7226-8

McMahan, E. A., \& Estes, D. (2010). Measuring lay conceptions of well-being: The beliefs about wellbeing scale. Journal of Happiness Studies, 12(2), 267-287. http://dx.doi.org/10.1007/s10902-010-9194-x

McMahon, D. M. (2006). Happiness: A history. New York, New York: Grove Press.

Marar, Z. (2003). Happiness paradox. London, UK: Reaktion Books.

Nussbaum, M. C. (2003). Capabilities as fundamental entitlements: Sen and social justice. Feminist Economics, 9(2-3), 33-59. http://dx.doi.org/10.1080/1354570022000077926

Nussbaum, M. C. (2008). Who is the happy warrior? Philosophy poses questions to psychology. The Journal of Legal Studies, 37(2), 81-113. http://dx.doi.org/10.1086/587438

Nussbaum, M. C. (2011). Creating capabilities: The human development approach. Cambridge, Massachusetts: The Belknap Press of Harvard University Press. http://dx.doi.org/10.4159/harvard.9780674061200

Nussbaum, M. C., \& Sen, A. (1993). The quality of life. (M. Nussbaum \& A. Sen, Eds.). Oxford University Press. http://dx.doi.org/10.1093/0198287976.001.0001

Parfit, D. (1984). Reasons and persons. Oxford, UK: Clarendon Press.

Raibley, J. R. (2011). Happiness is not well-being. Journal of Happiness Studies, 13(6), 1105-1129. http://dx.doi.org/10.1007/s10902-011-9309-z

Rosa, H. (2003). Social acceleration: Ethical and political consequences of a desynchronized high-speed society. Constellations, 10(1), 3-33. http://dx.doi.org/10.1111/1467-8675.00309

Rubenson, K., \& Desjardins, R. (2009). The impact of welfare state regimes on barriers to participation in adult education: A bounded agency model. Adult Education Quarterly, 59(3), 187-207.

http://dx.doi.org/10.1177/0741713609331548

Seligman, M. E. P. (2011). Flourish: A visionary new understanding of happiness and well-being. New York, New York: Atria Books.

Sen, A. (1985). Well-being, agency, and freedom: The Dewey lectures 1984. The Journal of Philosophy, 82(4), 169-221. http://dx.doi.org/10.2307/2026184

Sen, A. (1987). Commodities and capabilities. New Delhi, India: Oxford University Press.

Sen, A. (1999). Development as freedom. Oxford, UK: Oxford University Press. 
Van Praag, B. M. S., \& Ferrer-i-Carbonell, A. (2008). Happiness quantified: A satisfaction calculus approach. Oxford, UK: Oxford University Press.

\section{Appendix A: Interview Questions:}

1) Twenty-two years ago, I asked you to describe 'the good life'. You said, . How would you describe 'the good life' today? Has your idea of 'the good life' changed and, if so, why?

2) On a scale of 1 to 10, with 1 being "very unhappy" and 10 being "very happy," in general how happy would you say you are with your life?

3) On a scale of 1 to 10, how would you describe your life, with 1 being "very dull" and 10 being "very exciting," in general to what extent would you describe your life as dull or exciting?

4) On a scale of 1 to 10, how would you describe the extent to which your life is stressful, with 1 being "not at all stressful" and 10 being "very stressful," in general to what extent would you describe your life as stressful?

5) In the past few months, how healthy have you felt physically, with 1 being "very unhealthy" and 10 being "very healthy," in general to what extent would you describe yourself as physically healthy?

6) In the past few months, how healthy have you felt mentally, with 1 being "very unhealthy" and 10 being "very healthy," in general to what extent would you describe yourself as mentally healthy?

For each of these questions interview participants were asked to explain why they rated themselves the way they did and to discuss the factors that affected the rating.

The final question in this series was as follows:

7) What is or how do you define happiness? What is or how do you define wellbeing? Are these the same or different in your opinion? Explain. 


\section{Appendix B}

Table 4: Participants' responses to Likert-scale questions (1-10)

\begin{tabular}{|c|c|c|c|c|c|c|}
\hline $\begin{array}{l}\text { Participants' } \\
\text { responses to Likert- } \\
\text { scale questions (1-10) }\end{array}$ & & Happiness & $\begin{array}{l}\text { Excitement } \\
\text { in life }\end{array}$ & $\begin{array}{l}\text { Stress } \\
\text { in life }\end{array}$ & $\begin{array}{c}\text { Physical } \\
\text { health }\end{array}$ & $\begin{array}{l}\text { Mental } \\
\text { health }\end{array}$ \\
\hline Interview participants & Mean & 7.73 & 6.33 & 5.35 & 6.73 & 7.29 \\
\hline \multirow[t]{2}{*}{$\mathrm{N}=24$} & $\begin{array}{l}\text { Standard deviation } \\
\text { (SD) }\end{array}$ & 1.53 & 1.87 & 2.15 & 2.34 & 1.89 \\
\hline & Median & 8 & 6 & 5 & 8 & 8 \\
\hline Survey respondents & Mean & 7.82 & 6.83 & 6.45 & 7.16 & 7.09 \\
\hline \multirow[t]{2}{*}{$\mathrm{N}=574$} & $\begin{array}{l}\text { Standard deviation } \\
\text { (SD) }\end{array}$ & 1.52 & 1.61 & 1.92 & 1.83 & 1.84 \\
\hline & Median & 8 & 7 & 7 & 7 & 7 \\
\hline
\end{tabular}

